\title{
Produção de Alginato por Microrganismos
}

\author{
José Miguel Müller, Renata Lopes dos Santos, Riveli Vieira Brigido \\ Departamento de Engenharia Química e Engenharia de Alimentos, UFSC
}

\begin{abstract}
Resumo: $\mathrm{O}$ alginato é um copolímero linear constituído de unidades de ácidos $\alpha$-L-gulurônicos e $\beta$-D-manurônicos e é extensamente utilizado devido as suas propriedades espessantes, estabilizantes e gelificantes. Estas características fazem com que este biopolímero encontre aplicações na indústria de alimentos, na indústria têxtil e de papel, em cosméticos e na área farmacêutica e médica. Atualmente para este conjunto de aplicações sua principal fonte são algas marrons, entretanto, o alginato pode ser obtido a partir de biossíntese, utilizando-se microrganismos do gênero Pseudomonas e Azotobacter. A produção bacteriana de alginato apresenta-se como uma alternativa interessante e sua produção por microrganismos, além de possibilitar a produção de biopolímeros de alta qualidade com características específicas e pré-determinadas, irá diminuir o impacto ambiental nas regiões em que as algas marinhas das quais é extraído são coletadas. Nos últimos anos, vários estudos relacionados à produção de alginato por microrganismos foram realizados com o objetivo de avaliar sua produção e rota metabólica de biossíntese, para caracterizar o material produzido e para determinar as potencialidades de aplicação deste novo material. O rápido desenvolvimento de aplicações do alginato na área médica e farmacêutica, bem como a descoberta de propriedades imunológicas únicas deste material tem aumentado o interesse no desenvolvimento de processos para produzi-lo. Neste artigo são abordados aspectos relacionados à produção e as características do alginato bacteriano e também reportadas às potencialidades e aplicações inovadoras nas quais este material vem sendo utilizado.
\end{abstract}

Palavras-chave: Azotobacter, Pseudomonas, alginato, alginato bacteriano, biopolímero.

\section{Alginate Production by Microorganisms}

Abstract: Alginate is a linear copolymer consisting of units of $\alpha$-L-guluronic and $\beta$-D-mannuronic acid which is widely used due to its thickening, stabilizing and gelling properties. These characteristics mean that it has many applications in the food, textile, paper, cosmetics and pharmaceutical industries, as well as in the medical area. Currently, the main source of alginate for such applications is brown algae; however, this biopolymer can be obtained through biosynthesis, using micro-organisms of the genera Pseudomonas and Azotobacter. The bacterial production of alginate represents an interesting alternative since, in addition to enabling the production of high quality polymers with predetermined and specific characteristics, it can reduce the environmental impact in areas from which the seaweed is collected. In recent years, several studies related to the production of alginate by microorganisms have been performed to evaluate the production process and metabolic pathway of biosynthesis, to characterize the material produced and to determine the potential applications of this new material. The rapid development of new applications of alginate in the medical and pharmaceutical areas, as well as the discovery of the unique immunological properties of this material, has led to increased interest in finding novel processes for its production. This article examines aspects of the production of bacterial alginate and the characteristics of the material obtained, and also addresses potential and innovative applications for the use of this material.

Keywords: Azotobacter, Pseudomonas, alginate, bacterial alginate, biopolymer.

\section{Introdução}

O alginato foi caracterizado no final do século 19 e atualmente é obtido de algas marrons coletadas em regiões costeiras no mar. O alginato pode constituir até $40 \%$ da massa seca destas algas. Devido a suas propriedades únicas, para gelificar e espessar soluções e atuar como suporte de imobilização, o material tornouse um produto de importância comercial.

$\mathrm{O}$ alginato é amplamente utilizado em alimentos, cosméticos e medicamentos e também encontra aplicação na indústria têxtil e de papel. Atualmente vem sendo utilizado em aplicações inovadoras na área médica e farmacêutica. Em função de suas características é utilizado como espessante, estabilizante de emulsões e de espuma, agente de encapsulação, agente de gelificação, agente de formação de filmes e de fibras sintéticas entre outras possibilidades. O alginato utilizado atualmente é extraído de algas, entretanto a sua produção por microrganismos irá permitir uma exploração controlada de suas fontes naturais. Adicionalmente, a produção por microrganismos pode ser realizada sob condições controladas, usando substratos de qualidade constante e permitindo assim a obtenção de materiais específicos com características uniformes.

O alginato bacteriano foi descoberto em 1964, quando foi isolado a partir de uma cepa mucóide de Pseudomonas aeruginosa isolada de pacientes portadores de fibrose cística submetidos a tratamento com antibióticos ${ }^{[1]}$. Posteriormente foram identificadas bactérias do gênero Azotobacter e Pseudomonas como produtoras deste biopolímero.

A descrição da produção por Azotobacter foi realizada em $1966^{[2]}$. No início dos anos 80 foram identificados microrganismos do gênero Pseudomonas que não apresentaram patogenicidade e possuíam a capacidade de sintetizar alginato. Os microrganismos reportados foram $P$. florencens, $P$. mendocina e $P$. putida ${ }^{[3]}$.

A produção de alginato por microrganismos está associada ao desenvolvimento de uma característica mucóide fenotípica associada à formação de extensas colônias denominadas biofilmes $^{[4]}$. O alginato produzido por microrganismos apresenta características semelhantes ao extraído de algas e pode também ser utilizado como biomaterial em função de sua biocompatibilidade ${ }^{[5]}$. $\mathrm{O}$ alginato bacteriano pode substituir o material extraído de algas em suas aplicações tradicionais e sua utilização na área médica e farmacêutica vem sendo extensamente estudada devido à possibilidade de produzir materiais de alta pureza e também materiais que apresentem estruturas poliméricas especificas ${ }^{[6]}$. 


\section{Estrutura e Propriedades Físicas do Alginato}

$\mathrm{O}$ alginato é um copolímero linear constituído de ácidos $\alpha$-Lgulurônicos e $\beta$-D-manurônicos com ligações 1-4. O material varia extensamente em termos de sua proporção entre os resíduos manurônicos (M) e gulurônicos (G) bem como em sua estrutura sequencial e grau de polimerização. Desta forma, o material pode apresentar sequências alternadas de resíduos MG e blocos constituídos de dois ou mais resíduos $\mathrm{M}$ ou $\mathrm{G}^{[7]}$.

Para várias aplicações nas quais o material é utilizado é fundamental sua capacidade de formar géis, cujas características dependem da proporção $\mathrm{M} / \mathrm{G}$ e do número de ligações cruzadas entre as cadeias poliméricas. Os géis são formados na presença de cátions divalentes como $\mathrm{Ca}^{++}$ou $\mathrm{Mg}^{++}$e a presença de sequências de resíduos gulurônicos é necessária para que apresentem esta capacidade ${ }^{[6]}$. A interação entre os íons divalentes e os blocos gulurônicos forma a estrutura denominada "modelo caixa de ovos" $"[8]$.

No alginato produzido por bactérias estão presentes tanto os resíduos manurônicos como os gulurônicos. Os resíduos manurônicos podem estar ligados com grupos acetil, no carbono 2 e/ou 3, o que os torna parcialmente acetilados (Figura 1) ${ }^{[9]}$. Uma característica apresentada por alginatos produzidos por Pseudomonas é a ausência de resíduos ou de blocos constituídos de ácidos gulurônicos ${ }^{[7]}$.

As características estruturais do material afetam significativamente seu comportamento reológico. Assim, as propriedades reológicas do biopolímero sintetizado por bactérias estão associadas ao grau de polimerização, às complexas interações entre íons e os resíduos gulurônicos e manurônicos e ao grau de acetilação. A força do gel formado irá depender do número e da extensão dos blocos de resíduos gulurônicos ao longo da cadeia polimérica e da concentração de íons presentes ${ }^{[7]}$. A presença de grupos acetil confere ao material biossintetizado características viscoelásticas mais pronunciadas ${ }^{[10]}$.

\section{Biossíntese do Alginato por Microrganismos}

Na literatura, somente os gêneros Pseudomonas e Azotobacter são reportados como produtores de alginato, que para sua síntese utilizam diferentes fontes de carbono. A metabolização dos açúcares que formam sua estrutura segue a via de Entner-Doudurof, onde frutose ou frutose 1-6 bifosfato são convertidas em Frutose 6-fosfato que é metabolizada ao nucleotídeo manose 1-fosfato. O nuclotídeo é convertido em guanosina difosfato manose (GDPmanose) precursor do ácido manurônico que é a unidade monomérica do biopolímero $^{[6,11]}$.

A etapa de polimerização ocorre pela ação de um conjunto de proteínas localizadas na membrana citoplasmática. As enzimas que alteram a estrutura do alginato, como acetilases e epimerases, são encontradas no espaço periplásmico destes microrganismos ${ }^{[6]}$. As enzimas denominadas C-5 epimerases convertem os resíduos manurônicos em gulurônicos e as acetilases ligam o grupo acetil ao bloco manurônico ${ }^{[12]}$. A sequência de etapas de biossíntese é apresentada na Figura 2.

A cadeia polimérica formada é constituída inicialmente de resíduos manurônicos. Sequencialmente o polimanuronato é acetilado e epimerizado. Na etapa de acetilação, grupos acetil são ligados aos carbonos 2 e/ou 3 dos resíduos manurônicos ${ }^{[9,13]}$. Os fatores que a afetam esta etapa de biossíntese, não estão definidos para ambos os gêneros e a presença de grupos acetil sugere uma proteção da ação de epimerases ${ }^{[5,14]}$.

A ação de epimerases converte o ácido $\alpha$-L-manurônico em seu C-5 epímero, ácido $\beta$-D-gulurônico. Para o gênero Azotobacter foram identificadas sete epimerases que apresentam diferentes padrões para conversão destes resíduos, cuja atividade está associada a concentração de cálcio no meio de cultura. Para Pseudomonas foi somente identificada uma epimerase e os fatores que afetam sua atividade ainda não foram definidos ${ }^{[15]}$. As epimerases podem ser divididas em dois grupos: um que gera somente blocos alternados (MG) e outro que forma blocos de resíduos gulurônicos (GG). A ação destas enzimas possibilita a elaboração de alginatos que não apresentam blocos de resíduos manurônicos $(\mathrm{MM})^{[16]}$.

Os genes necessários para biossíntese de alginato, denominados alg, estão distribuídos no Grupo I de homologia de Pseudomonas da linhagem Azotobacter-Azomonas ${ }^{[17]}$. Estudos realizados com estas bactérias indicam que o controle da biossíntese de alginato em Pseudomonas aeruginosa, envolve pelo menos 24 genes, sendo que dois, alg 8 e alg 44, apresentam papel fundamental no processo de polimerização. A ordem física e a distribuição dos genes alg em Pseudomonas e A. vinelandii são idênticas as encontradas em Pseudomonas aeruginosa ${ }^{[5,17]}$.

Modificações genéticas indicam que a ausência de um único destes genes é suficiente para que o microrganismo produza somente ácidos urônicos ${ }^{[18]}$. Estudos observaram também que em Pseudomonas a ausência do gene alg $G$ faz com que o alginato produzido possua somente resíduos manurônicos ${ }^{[19]}$.

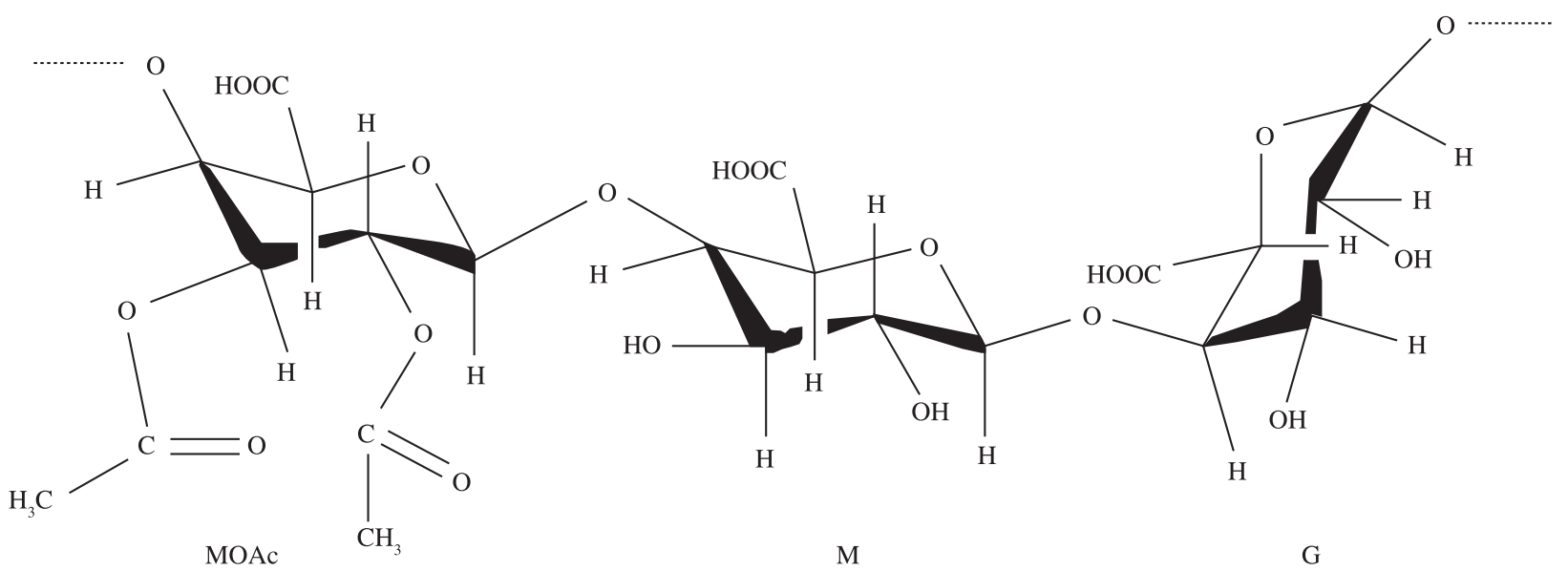

Figura 1. Alginato sintetizado por micro-organismos. MOAc: resíduo manurônico acetilado; M: resíduo manurônico; e G: resíduo gulorônico. 


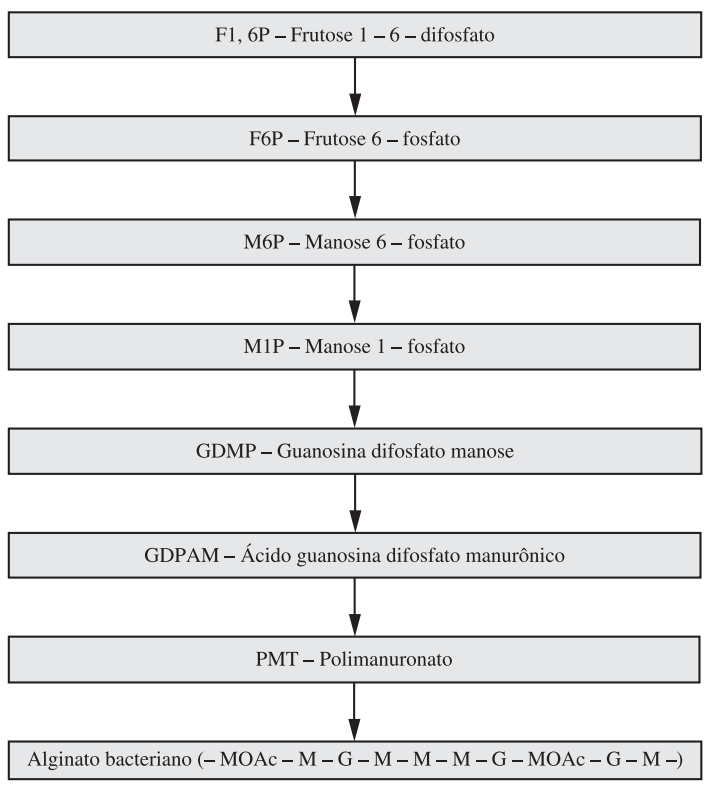

Figura 2. Rota metabólica de biossíntese de alginato em bactérias. MOAc: resíduo manurônico acetilado; M: resíduo manurônico; e G: resíduo gulurônico.

\section{Produção de Alginato por Bactérias}

$\mathrm{O}$ crescente uso do alginato em diferentes aplicações aumentou o interesse em avaliar as funções biológicas e fisiológicas relacionados à biossíntese do polímero pelos microrganismos. Nestes estudos, busca-se também entender melhor as rotas metabólicas utilizadas pelos microrganismos para controlar a regulação, formação e composição do material biossintetizado e a otimização de seu processo de produção ${ }^{[5,20]}$.

Pesquisas relacionadas ao estudo da estrutura do biopolímero indicam que o alginato sintetizado pelos gêneros Pseudomonas e Azotobacter é parcialmente acetilado e que os grupos acetil estão exclusivamente associados aos resíduos manurônicos. Adicionalmente, blocos de resíduos gulurônicos (GG) são somente encontrados em alginatos sintetizados pelo gênero Azotobacter ${ }^{[7]}$.

Fatores relacionados com a composição do meio de cultura, proporção entre carbono e nitrogênio, nível de agitação, temperatura, transferência de oxigênio são reportadas em vários estudos relacionados a produção de alginato por ambos gêneros em frascos agitados e biorreatores.

Para produção de alginato por A. vinelandii um fator de importância é o suprimento de oxigênio em faixas de concentração bem definidas. A tensão de oxigênio dissolvido deve permanecer em uma faixa bastante estreita para uma ótima produção de massa celular e alginato, pois, sob condições de limitação de oxigênio, o micro-organismo produz polihidroxibutirato ${ }^{[6]}$.

$\mathrm{O}$ efeito da limitação de outros fatores de crescimento foram também avaliados na produção de alginato por Azotobacter. Alguns resultados interessantes, como alta taxa específica de produção de alginato, foram obtidos pela limitação de fosfato, ferro e /ou molibdênio. Em culturas de batelada alimentada com limitação da fonte de carbono o alginato foi também produzido a taxas similares, apresentado resíduos gulurônicos e alta massa molecular ${ }^{[6]}$.

Na produção de alginato por Pseudomonas, o efeito de fatores como fonte de carbono, relação carbono/nitrogênio e o efeito de constituintes do meio de cultivo sobre a produção de alginato, tem sido avaliados. Nestes estudos é reportado o uso de técnicas de resistência a antibióticos e/ou uso de agentes mutagênicos para seleção dos microrganismos produtores ${ }^{[21,22]}$.

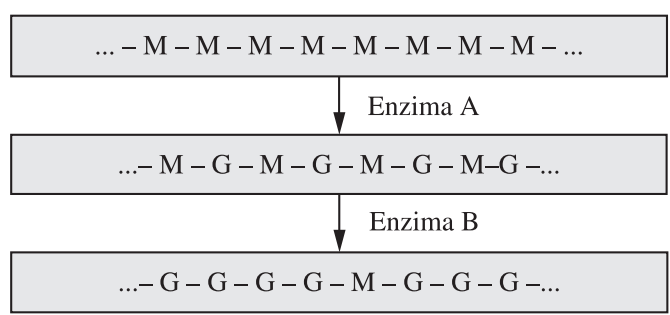

Figura 3. Conversão de alginatos por enzimas. a) sequência de ácidos manurônicos; b) sequência de blocos alternados; e c) sequência com blocos gulurônicos. Enzima A e B, C5-epimerases.

\section{Modificações Químicas e Enzimáticas}

As propriedades do alginato bacteriano são determinadas pelo seu grau de polimerização, acetilação e distribuição dos resíduos manurônicos e gulurônicos ao longo da cadeia polimérica.

Atualmente é possível produzir materiais com características previamente determinadas, ajustando-se as condições de cultura, através de manipulações genéticas nos microrganismos produtores e por de processos in vitro que utilizam enzimas liases ou epimerases. Este conjunto de possibilidades permite a elaboração de alginatos com composição definida ${ }^{[15]}$.

As epimerases são muito eficientes no controle da composição e sequência dos resíduos presentes na estrutura polimérica do alginato e através de seu uso é possível modificar a estrutura de alginatos sintetizados por microrganismos ou extraídos de algas marinhas ${ }^{[19]}$.

Um exemplo é a modificação de alginatos sintetizados por Pseudomonas, constituídos majoritariamente por resíduos manurônicos, por enzimas epimerases como ilustrado na Figura 3. As enzimas A e B (Figura 3) são C-5 epimerases que apresentam diferentes padrões de conversão dos resíduos manurônicos. Enquanto um grupo converte resíduos vizinhos, produzindo blocos de gulurônicos, o outro grupo não apresenta esta capacidade. Desta forma, a partir de um material isento de resíduos gulurônicos, pode-se estabelecer padrões sequenciais de resíduos gulurônicos ou materiais isentos de blocos manurônicos ${ }^{[23]}$. O conhecimento da biossíntese do alginato e particularmente da possibilidade de modificá-lo abre novas oportunidades no campo da engenharia metabólica para desenhar alginatos com propriedades préestabelecidas, principalmente para aplicações na área médica ${ }^{[15]}$.

Outros materiais de interesse também podem ser obtidos por modificação química do alginato, pois existe um grande interesse em desenvolver novos materiais poliméricos. Pesquisas recentes na modificação química do alginato reportam a elaboração de materiais compósitos com sulfato de cálcio, com quitosana ou com polímeros acrílicos que apresentam aplicações de interesse especial em sistemas para liberação controlada de medicamentos ${ }^{[24]}$.

\section{Aplicações do Alginato}

Atualmente a produção de alginato em escala comercial está restrita a sua obtenção a partir de algas marinhas e os principais usuários deste material são a indústria de alimentos e a indústria têxtil e de papel.

A indústria de alimentos utiliza a maior parte do alginato produzido atualmente. Entre suas aplicações usuais estão o uso em sorvetes, em produtos lácteos e misturas para bolos. $\mathrm{O}$ alginato encontra aplicações também na indústria de bebidas onde é utilizado para melhorar as características sensoriais destes produtos. Em cervejas estabiliza a espuma e na elaboração de sucos pode ser utilizado para manter os constituintes da mistura em suspensão ${ }^{[6]}$. 
$\mathrm{Na}$ indústria têxtil a utilização do alginato melhora o desempenho das tintas utilizadas nos processos de impressão favorecendo a aderência e a deposição destes materiais sobre os tecidos. Na indústria de papel a adição de alginato permite que as propriedades para impressão destes materiais também melhorem ${ }^{[6]}$.

Algumas aplicações promissoras do alginato incluem sua utilização em filmes bioativos para cobertura de alimentos e na elaboração de alimentos reestruturados onde pode ser utilizado em polpas de frutas, de vegetais e em carnes. A adição de alginato em massas proporciona um melhoramento das propriedades de pasta, modifica as características reológicas e a textura do material, retarda a retrogradação e aumenta a capacidade de hidratação do amido ${ }^{[25]}$.

$\mathrm{O}$ alginato é utilizado em aplicações na área médica. Vários produtos farmacêuticos são imobilizados em alginato. Sua utilização como excipiente de liberação de medicamentos, curativos inteligentes, em formulações para prevenção de refluxo gástrico, bem como materiais de impressão dental, já é conhecida.

Estudos recentes avaliam o potencial de estruturas homopoliméricas de alginato. Entre aplicações reportadas na literatura para estes materiais, está o estímulo a células do sistema imune, como citoquinas, interleucina 1, interleucina 6 e fator de necrose tumoral alfa, cuja resposta está associada à estrutura sequencial de biopolímeros constituídos exclusivamente de grupos manurônicos ${ }^{[6]}$. Estruturas constituídas somente de grupos gulurônicos foram propostas para o tratamento de pacientes portadores de fibrose cística em função de sua capacidade de modificar as características reológicas da mucina ${ }^{[26]}$.

O alginato apresenta boas características para formação de nanocápsulas e tem sido extensamente avaliado para formação de partículas com tamanhos na faixa de 100 a $2 \mathrm{~mm}$ para liberação de diferentes materiais ${ }^{[27]}$. Nanopartículas contendo alginato, usadas na liberação controlada de inibidores de proteases ${ }^{[28]}$ e na liberação de insulina ${ }^{[29]}$, apresentaram bom desempenho na liberação destes medicamentos. Algumas proposições são inovadoras, como, por exemplo, seu uso em partículas inaláveis ou em partículas magnéticas. A avaliação de nanopartículas inaláveis de alginato indicou que o material pode ser um carreador ideal para medicamentos no tratamento de doenças respiratórias ${ }^{[30]}$. A combinação das propriedades magnéticas de nanopartículas de ferro com a biocompatibilidade do alginato resultou em um material que pode ser usado como suporte de medicamentos cuja liberação pode ser controlada através de estímulos externos ${ }^{[31]}$.

O biopolímero é usado na elaboração de hidrogel de alginato, material utilizado em engenharia tecidual. Trata-se de um suporte tridimensional para células, também conhecido como scaffold, cujas características de firmeza, ligação e liberação de moléculas bioativas e de dissolução podem ser controladas a partir de modificações físico-químicas do biopolímero ou mesmo sobre os géis formados a partir do alginato ${ }^{[32]}$. Um exemplo desta possibilidade é a imobilização de células tronco em scaffolds construídos com alginato, onde observou-se que materiais com maiores proporções de resíduos gulurônicos são mais adequados para este fim ${ }^{[33]}$.

$\mathrm{O}$ alginato tem sido também utilizado em combinação com outros materiais principalmente nas áreas biotecnológica e biomédica. Compósitos de alginato como alginatoPEGAc (alginato de polietilenoglicol acrilato), um gel que combina as propriedades do alginato com as características mucoadesivas do polietilenoglicol, demonstram que o material não apresenta citotoxicidade $^{[34]}$. Compósitos de colágeno, contendo albumina encapsulada em esferas de alginato foram utilizados como suporte para o crescimento de células epiteliais da córnea; o material obtido apresentou biocompatibilidade e excelentes características de claridade ótica e resistência mecânica ${ }^{[35]}$.
Novas possibilidades de aplicação de alginatos de alta qualidade envolvem sua utilização no transplante de células. Entre os estudos apresentados na literatura é reportada sua utilização para imobilizar células produtoras de insulina para reversão de diabetes tipo I e para elaborar cápsulas de alginato/poli-L-lisina contendo Ilhotas de Langerhans, que são avaliadas atualmente como pâncreas endócrino bioartificial ${ }^{[6,26]}$. Um gel formado por alginato modificado com peptídeos para permitir sua ligação com heparina, também é reportado como suporte para liberação controlada de fatores angiogênicos. Os estudos demonstraram o potencial terapêutico deste material na promoção da angiogênese, bem como na engenharia tecidual ${ }^{[36]}$.

Para o conjunto de aplicações do alginato, os materiais extraídos de diferentes partes das algas, ou submetidos a fracionamento, atendem a maioria das necessidades. Entretanto, algumas aplicações na área médica e farmacêutica necessitam de materiais homogêneos com características específicas, que somente podem ser obtidos pela produção do material por microrganismos.

$\mathrm{O}$ entendimento de fatores que determinam as propriedades do alginato bacteriano, como a distribuição e sequência dos blocos que o constituem, grau de acetilação e a possibilidade de modificar sua estrutura, irá ampliar as possibilidades de projetar alginatos para aplicações específicas ${ }^{[5]}$.

\section{Aspectos Econômicos e Produção Industrial}

O alginato extraído de algas é comercializado por US\$5-20 kg-1, para suas aplicações usuais ${ }^{[5]}$. A produção de alginato bacteriano, pode ter por referência outros biopolímeros já comercializados, entre os quais se encontram xantana e gelana.

Os custos de produção de biopolímeros dependem do rendimento obtido da fonte de carbono utilizada, dos custos relativos ao processo de produção e de etapas posteriores de separação. A possibilidade de usar fontes de carbono de resíduos de processos industriais, como glicerol, melaços ou soro de queijo, apresenta-se também como uma opção interessante para redução de custos.

A aplicação final do biopolímero também é determinante nos custos do material, pois os processos de purificação, conhecidos como processos de downstream, são os que mais contribuem no preço de comercialização do produto.

Para produção industrial deste biopolímero é importante otimizar o processo de produção, de forma a alcançar rendimentos apresentados por biopolímeros como a xantana, cuja concentração chega a 30 g.L L $^{-1}$ no meio de fermentação ${ }^{[5]}$. Estudos realizados com Azotobacter vinelandii ou Pseudomonas reportam concentrações menores do biopolímero ao final do processo fermentativo para ambos os gêneros. Os melhores parâmetros de concentração de biopolímero, rendimento de bioconversão e produtividade, reportados em processos de produção de alginato são mostrados na Tabela 1.

Os resultados referem-se a experimentos realizados em laboratório em fermentadores cujo volume útil é de até $5 \mathrm{~L}$. A produção de alginato em escala piloto, com Pseudomonas sp. modificada geneticamente, foi recentemente iniciada pela empresa Progenesis Technologies LLC incubada na Universidade de Marshall nos EUA, entretanto não são informados detalhes do processo no site da empresa.

\section{Perspectivas Futuras para Produção de Alginato Bacteriano}

As principais fontes para produção comercial de alginato são algas marinhas. As algas das quais é extraído, Laminaria hyperborea e Macrocystis pyrifera, fazem parte de um exuberante ecossistema 
Tabela 1. Parâmetros de produção de alginato para os gêneros Pseudomonas e Azotobacter.

\begin{tabular}{|c|c|c|c|}
\hline Micro-organismo & $\mathbf{P}\left(\mathbf{g} \cdot \mathbf{L}^{-1}\right)$ & $Y_{P / S}\left(g \cdot g^{-1}\right)$ & $\mathbf{Q}\left(\mathbf{g} \cdot \mathbf{L}^{-1} \cdot \mathbf{h}^{-1}\right)$ \\
\hline Azotobacter vinelandii DSMZ 93-541b ${ }^{[20]}$ & 4,9 & 0,12 & 0,2 \\
\hline Azotobacter vinelandii NCBI $9068^{[37]}$ & 6,2 & 0,31 & 0,06 \\
\hline Pseudomonas mendocina NCIB $11687^{[38]}$ & 23,5 & 0,36 & ND \\
\hline Pseudomonas mendocina CCT $2245^{[21]}$ & 8,95 & 0,44 & 0,407 \\
\hline Pseudomonas putida $1582^{[39]}$ & 2,2 & ND & 0,044 \\
\hline
\end{tabular}

P: concentração de alginato $\left(\mathrm{g} . \mathrm{L}^{-1}\right) ; \mathrm{Y}(\mathrm{p/s})$ : rendimento de bioconversão $\left(\mathrm{g} \cdot \mathrm{g}^{-1}\right)$; e Q: produtividade $\left(\mathrm{g} \cdot \mathrm{L}^{-1} \cdot \mathrm{h}^{-1}\right)$

marinho conhecido como floresta de kelp. Estas florestas, que desenvolvem-se em latitudes de 40 a $60^{\circ}$ em ambos hemisférios, são um ambiente cuja complexidade espacial as torna um bercário para animais como anfípodes e peixes predadores.

Estudos realizados na costa da Califórnia ${ }^{[40]}$ e na Tasmânia ${ }^{[41]}$ mostram que a capacidade adaptativa deste ecossistema vem sendo afetada pelas mudanças climáticas e pela pesca comercial. A sobrepesca desencadeou um aumento da população de herbívoros, como ouriços do mar, cuja principal fonte de alimento são as florestas de kelp. O sobrepastoreio criou áreas do leito marinho desnudas de algas e cobertas de ouriços. Nestes estudos, em função do aquecimento do oceano e da remoção sem precedentes de predadores, é também enfatizada a necessidade urgente de restaurar as populações importantes da floresta de kelp.

Desta forma, a crescente preocupação em minimizar o impacto da ação humana sobre este ecossistema torna a produção de alginato por microrganismos uma opção interessante. Adicionalmente, a possibilidade de produzir alginatos de alta qualidade com características pré-determinadas fazem com que alginato bacteriano apresente vantagens sobre o material extraído de algas.

Um melhor entendimento dos mecanismos de síntese por ambos os gêneros irá permitir que estratégias de produção possam ser delineadas, possibilitando a elaboração de materiais para aplicações específicas, principalmente na área médica e farmacêutica.

Uma possibilidade interessante é a produção de polimanuronatos utilizando microrganismos que não apresentam o gene alg $G$ que codifica enzimas epimerases ${ }^{[19]}$. Estes biopolímeros constituídos somente de resíduos manurônicos podem ser posteriormente modificados in vitro por epimerases. Esta sequência de etapas apresenta-se como estratégia a ser explorada para projetar alginatos com características estruturais específicas em termos da proporção e sequência desejada de resíduos manurônicos e/ou gulurônicos ${ }^{[6,15]}$.

Outras características do material produzido, entre as quais, o grau de acetilação e massa molecular do biopolímero, também podem ser controladas durante o processo de biossíntese e abrir novas possibilidades para sua utilização ${ }^{[6]}$.

Os conhecimentos obtidos nas últimas décadas, com relação à biossíntese de alginato por microrganismos torna provável que este material venha a ser o próximo biopolímero produzido em escala industrial, uma vez que materiais com características especificas como alginatos de alta pureza utilizados na área farmacêutica podem alcançar preços de até US\$ $40.000 \mathrm{~kg}^{-1[5]}$.

Atualmente há uma demanda crescente de materiais projetados a partir de biopolímeros bacterianos para aplicações específicas. Adicionalmente, a vantagem competitiva de desenvolver processos ambientalmente amigáveis para produzir materiais biodegradáveis e, em alguns casos, materiais biocompatíveis, torna-se cada vez mais atrativa para a indústria. Neste contexto, o uso de bactérias proporciona um campo de pesquisa crescente para produzir e projetar biopolímeros com propriedades específicas ${ }^{[42]}$.

\section{Referências Bibliográficas}

1. Linker, A. \& Jones, R. S. - Nature, 204, p.187 (1964). http://dx.doi. org/10.1038/204187a0

2. Gorin, J. P. A. \& Spencer, T. J. F. - Can. J. Chem., 44, p.993 (1966). http://dx.doi.org/10.1139/v66-147

3. Govan, J. R. W.; Fyfe, J. A. M. \& Jarman, T. R. - J. of Gen.. Microbiol., 1125, p.217 (1981).

4. Costerton, J. W. - TrendsMicrobiol., 9, p.50 (2001). http://dx.doi. org/10.1016/S0966-842X(00)01918-1

5. Remminghorst, U. \& Rehm, B. H. A. - Biotechnol. Lett.,28, p.1701 (2006). http://dx.doi.org/10.1007/s10529-006-9156-x

6. Sabra, W.;Zeng, A. P. \& Deckwer,W. D. - Appl. Microbiol. Biotechnol., 56, p.315 (2001). http://dx.doi.org/10.1007/s002530100699

7. Skjak-Braek, G.; Grasdalen, H. \& Larsen, B. - Carbohydr. Res., 154, p.239 (1986)

8. Grant, G. T.; Morris, E. R.; Ress, D.A.; Smith, P .J. C. \& Thom, D. - FEBS Letters, 32, p.195 (1973). http://dx.doi.org/10.1016/00145793(73)80770-7

9. Rehm, B. H. A. \& Valla, S. - Appl. Microbiol. Biotechnol., 48, p.281 (1997). http://dx.doi.org/10.1007/s002530051051

10. Moresi, M.; Bruno, M. \& Parente, E. - J. Food Eng., 64, p.179 (2004). http://dx.doi.org/10.1016/j.jfoodeng.2003.09.030

11. Ertesvåg, H. \& Valla, S. - Pol. Degrad. Stabil., 59, p.85 (1998).

12. Haug, A. \& Larsen, B. - Bochim. Biophys.Acta.,192, p.557 (1969).

13. Anderson, A. J.; Hacking, A. J. \& Daves, E. A. - J. Gen. Microbiol., 133, p.1045 (1987).

14. Fyfe J. A. M. \& Govan, J. R. W. - Prog. Ind. Microbiol.,18, p. 45 (1983).

15. Ertesvåg, H.; Hoidal, H. K.; Scherven, H.; Svanem, B. I. G. \& Valla, S. - Metab. Eng., 1, p.262 (1999).

16. Gimmestad, M.; Steingedal, M.; Ertesvåg, H.; Moreno, S.; Christensen, G. E. \& Valla, S. - J Bacteriol., 188, p.5551 (2006). http://dx.doi. org/10.1128/JB.00236-06

17. Ahmed, M. N. - Cur. Genom.,8, p.191 (2007).

18. Jain, S. \& Ohman, D. E. - J. Bacteriol. 180, p.634 (1998).

19. Gimmestad, M.; Sletta, H.; Ertesvåg, H.; Bakkevig, K.; Jain, S.; Suh, S.; Skjåk-Braek, G.; Ellingsen, T. E. Ohman, D. E. \& Valla, S. - J. Bacteriol., 185, p.3515 (2003). http://dx.doi.org/10.1128/ JB.185.12.3515-3523.2003

20. Sabra, W. A.; Zeng, A. P.;Sabry, S.; Omar, S. \& Deckwer, W. D. - Appl. Microbiol., 52, p.773 (1999).

21. Müller, J. M. \& Monte Alegre, R. - World J. Microbiol. Biotech., 23, p.691 (2007)

22. Hacking, A. J.; Taylor, I. W. F.; Jarman, T. R. \& Govan, J. R. W. - J. Gen. Microbiol., 1129, p.3473 (1983).

23. Mørch, Y. A.; Donati, I.; Strand, B. L. \& Skjåk-Bræk, G. Biomacromol.,8, p.2809 (2007)

24. Ayala, G. G.; Malinconico, M. \& Laurienzo, P. - Molecules., 13, p.2069 (2008) 
25. Lee, S.; Bae, I. N.; Jung, J.; Jang, K.; Kim, Y. W. \& Lee, H. G. - J. Text. Stud., 39, p.393 (2008). http://dx.doi.org/10.1111/j.17454603.2008.00149.x

26. Draget, K. \& Taylor, C. - Food Hydrocoll., 23, p.1 (2009).

27. Lertsutthiwong, P.; Noomun, K.; Jongaroonngamsang, N.; Rojsitthisak, P. \& Nimmannit, U. - Carbohy. Pol., 74, p.209 (2008). http://dx.doi. org/10.1016/j.carbpol.2008.02.009

28. Angshuman, B.; Bhadttacharjee, S. K.; Mahanta, R.; Biswanath, M. \&Bandyopadhayay, S. K. - J. Glob. Pharma. Techn.,2, p.126 (2010).

29. Sarmento, B.; Ribeiro, A. J.; Veiga, F.; Ferreira, D. C. \& Neufeld, R. J. - J. Nanosc. Nanotech.,7, p.2833 (2007). http://dx.doi.org/10.1166/ jnn.2007.609

30. Ahmad, Z.; Sharma, S. \& Khuller, G. K. - Int. J. Antimicrob. Agents., 4, p.298 (2005)

31. Finotelli, P. V.; Sampaio, D. A.; Morales, M. A.; Rossi, A. M. \& RochaLeão, M. H. - Braz. J. Chem. Eng., 25, p.443 (2008).

32. Augst, A. D.; Kong, H. J. \& Mooney, D. J. - Macromol. Biosci.,6, p.623 (2006). http://dx.doi.org/10.1002/mabi.200600069

33. Purcell, E. K.; Singh, A. \&Kipke, D. R. - Tissue Eng., 15, p.541 (2009).

34. Davidovich-Pinhas, M. \& Bianco-Peled, H. - Acta Biomat.,7, p. 625 (2011). http://dx.doi.org/10.1016/j.actbio.2010.09.021
35. Liu, W.; Griffith, M. \& Li, F. - J. Mater. Sci: Mater. Med., 19, p.3365 (2008). http://dx.doi.org/10.1007/s10856-008-3486-2

36. Lee, K. Y.; Nishishita, N.; Hirano, Y. \& Mooney, D. - Key Eng. Mat., 342-343, p.517 (2007). http://dx.doi.org/10.4028/www.scientific. net/KEM.342-343.517

37. Chen, W. P.; Chen, J. Y.; Chang, S. C. \& Su, C. L. - App. Env. Microb., 49, p.543 (1985).

38. Hacking, A. J.; Taylor, W. F.; Jarman, T. R. \& Govan, J. R. W. - J. Gen. Microbiol., 129, p.3473 (1983).

39. Conti, E.; Flaibani, A. O'Regan, M. \& Sutherland, I. W. Microbiol., 140, p.1125 (1994). http://dx.doi.org/10.1099/13500872140-5-1125

40. Linga, S. D.; Johnson, C. R.;Frusherb, S. D.; Ridgway, K. R.; Purcell, E. K.; Singh, A. \& Kipke, D. R. - PNAS, 106, p.22341 (2009).

41. Steneck, R. S.; Vavrinec, J. \& Leland, A.V. - Ecosyst., 7, p.323 (2004).

42. Rehm, B. H. A.- Nature, 8, p.578 (2010).

Enviado: $23 / 08 / 10$

Reenviado: $25 / 01 / 11$

Aceito: 07/02/11

DOI: $10.1590 / \mathrm{S} 0104-14282011005000051$ 